\title{
Petrol Fiyatı ve Döviz Kurunun Gıda Fiyatları Üzerine Asimetrik Etkisi: Türkiye Örneği
}

\author{
Cem Gokce ${ }^{\mathrm{a}}$
}

Öz: Ekonomik istikrarın önündeki engellerden biri yüksek enflasyondur. Enflasyonun belirleyici faktörleri arasında da gıda enflasyonu sayılabilir. Bu çerçevede çalışmanın amacı, Türkiye'de petrol fiyatlarının ve döviz kurunun gıda fiyatları üzerindeki etkisini incelemektir. Çalışmada petrol fiyatlarının ve döviz kurunun gıda fiyatları üzerinde asimetrik etkisi olduğu öngörüsü çerçevesinde NARDL (Doğrusal Olmayan Otoregresif Dağıtılmış Gecikme) yöntemi uygulanmıştır. Çalışmada Ocak 2010- Aralık 2019 dönemine ilişkin aylık veriler kullanılmıştır. Elde edilen temel bulgular beklenti çerçevesinde gerçekleşmiştir. Bulgular, petrol fiyatlarının ve döviz kurunun gıda fiyatları ile uzun dönemde asimetrik ilişki içerisinde olduğunu göstermektedir. Kısa dönemde ise asimetrik bir ilişki tespit edilememiştir. Ayrıca uzun dönem katsayılar incelendiğinde, petrol fiyatlarının ve döviz kurunun pozitif değişimlerinin istatistiksel olarak anlamlı olduğu görülmektedir. Petrol fiyatı ve döviz kurundaki pozitif değişimler gıda fiyatlarını aynı yönde etkilemektedir. Petrol fiyatları 1 ABD Doları arttığında gıda fiyat endeksi 0,30 birim, Dolar kuru 1 TL arttığında ise gıda fiyat endeksi 16,6 birim artmaktadır. Bu bulgular çerçevesinde bir politika önerisi olarak; petrol fiyatlarındaki ve döviz kurlarındaki pozitif şokların gıda fiyatlarına geçişkenliğini azaltacak tedbirlerin alınması gerekmektedir.

\section{Asymmetric Effect of Oil Price and Exchange Rate on Food Prices: The Case of Turkey}

\begin{abstract}
One of the obstacles to economic stability is high inflation. Food inflation can be considered among the determining factors of inflation. In this context, the study aims to examine the effect of oil prices and exchange rates on food prices. In the study, NARDL (NonLinear Autoregressive Distributed Lag) method was applied to predict that oil prices and exchange rates may have an asymmetric effect on food prices. Monthly data from January 2010 to December 2019 were used in the study. The main results achieved were realized within the framework of expectations. The results show that oil prices and exchange rates are in an asymmetrical relationship with food prices in the long run. In the short term, an asymmetrical relationship was not detected. Also, when the long-term coefficients are analyzed, it is seen that positive changes in oil prices and exchange rates are statistically significant. Positive changes in oil price and exchange rate affect the dependent variable in the same direction. If oil prices increase by 1 U.S. Dollar, the food price index increases by 0.30 units, and when the U.S. Dollar rate increases by 1 TL (Turkish Lira), the food price index increases by 16.6 units. As a policy recommendation within the framework of these results, precautions should be taken to reduce the pass-through of positive shocks in oil prices and exchange rates to food prices.
\end{abstract}

Anahtar Sözcükler: Petrol Fiyatları, Döviz Kurları, Gıda Fiyatları, NARDL Modeli, Asimetri

JEL: E31, Q11, Q31, Q43

$\begin{array}{ll}\text { Geliş } & : 25 \text { Mart } 2021 \\ \text { Düzeltme } & : 26 \text { Mayıs } 2021 \\ \text { Kabul } & : 28 \text { Haziran } 2021 \\ \text { Tür } & : \text { Araştırma }\end{array}$

Keywords: Oil Prices, Exchange Rates, Food Prices, NARDL Model, Asymmetry

JEL: E31, Q11, Q31, Q43
Received : 25 March 2021

Revised : 26 May 2021

Accepted : 28 June 2021

Type : Research

a Asst. Prof., PhD., Afyon Kocatepe University, Faculty of Economics and Administrative Sciences, Departments of Economics, Afyonkarahisar, Turkiye, cgokce@aku.edu.tr (ORCID ID: 0000-0001-7805-6977) 


\section{Giriş}

Yüksek oranlı enflasyon özellikle gelişmekte olan ülke ekonomileri açısından önemli sorunlardan biridir. Enflasyonun ekonomilere olumsuz etkileri özellikle 1970'lerde yaşanan petrol krizlerinden sonra ortaya çıkan stagflasyondan bu yana literatürde tartışılmaktadır. Gıda fiyatları, genel enflasyonun belirleyicilerinden olarak kabul edilmektedir. Türkiye'de Türkiye İstatistik Kurumu (TÜiK) tarafından hesaplanan tüketici fiyat endeksinin alt gruplarından en büyüğü de gıda fiyatlarıdır (TUiK, 2021). 2021 yılı için tüketici fiyat endeksi (TÜFE) ana harcama grubu ağılıkları içerisinde $\% 25,94$ pay ile gıda grubu açık ara farkla birinci sırada bulunmaktadır. 2020 yılının başından bu yana yaşanan ve tüm dünyayı etkileyen pandemi sürecinde dünya da yaşanan durgunluğa rağmen Türkiye'de enflasyonun yüksek seyretmesinin en önemli nedenlerinden biri de gıda fiyatlarında yaşanan artıştır. Türkiye Cumhuriyet Merkez Bankası (TCMB) (2021) 2020 yılı enflasyon raporunda; döviz kuru ve gıda fiyatlarındaki sert yükselişlerin enflasyonun öngörülenden yüksek seyretmesine sebep olduğu değerlendirmesi yer almaktadır.

Gıda fiyatlarının olumsuz etkilerine yönelik tecrübeler geçmiş dönemlerde de yaşanmıştır. 2007-2008 döneminde Amerika Birleşik Devletleri'nde (ABD) gıda fiyatlarındaki hızlı yükselişin arkasında yatan temel sebeplerin tarımsal emtia fiyatları ve enerji fiyatlarının artması olduğu ifade edilmektedir (Baek ve Koo, 2010). Gıda fiyat dalgalanmalarının makroekonomik etkileri, ithalat ve ihracat üzerinden ödemeler dengesi, bütçeler, enflasyon ve yoksulluk dahil olmak üzere geniş ve kapsamlı olabilmektedir (Roache, 2010). Tarım sektörünün ekonomik kalkınma açısından önemli bir rolü vardır. Tarım ürünleri temel ihtiyaçların tatminini sağlayan ve her gelir grubundan insanın tüketimine konu olan ürünlerdir.

Petrol günümüzde ekonomi üzerinde oldukça ciddi etkileri olan bir enerji kaynağıdır. Tarım sektörü açısından önemli bir girdi konumunda bulunan petrolün fiyat dalgalanmalarının sektöre etkisi olasıdır. Modern tarım, gıda üretiminin ve pazarlamasının her aşamasında büyük ölçüde fosil yakıt kullanımına dayanmaktadır (Arshad ve Hameed, 2009). Ham petrol fiyatları, diğer emtia fiyatlarını çeşitli şekillerde etkilemektedir. Arz tarafında, ham petrol, çoğu birincil emtianın toplam üretim fonksiyonu içerisinde yer almaktadır. Talep tarafında ise taşımacılık açısından bir girdidir (Baffes, 2007).

Petrol fiyatlarındaki değişimlerin gıda fiyatlarına üç kanaldan etki ettiği düşünülmektedir. İlk olarak, tarım sektöründeki girdi maliyetleri petrol fiyatlarından etkilenmektedir. Alvarez vd. (2011) petrol fiyatlarının enflasyon üzerindeki dolaylı etkisini, petrol ürünlerini girdi olarak kullanan mal ve hizmetlerin üretim maliyetindeki değişim ve perakende fiyatlarına geçişi olarak tanımlamaktadır. Petrol fiyatlarındaki değişimler, ulaşım maliyetlerini doğrudan etkileyen gübre ve yakıt gibi enerji yoğun girdileri etkileyerek gıda üretim maliyetlerini ve dolayısıyla gıda fiyatlarını doğrudan etkilemektedir (Baumeister ve Kilian, 2014). İkincisi, petrol fiyatları tarım ürünlerinin taşıma maliyetlerine etki etmektedir. Üçüncüsü ise, petrol fiyatlarındaki değişimler alternatif enerji kaynaklarına (biyoenerji gibi) olan talebi etkileyeceğinden tarım ürünleri talebi ve fiyatı da etkilenmektedir. Petrol fiyatlarındaki dalgalanmalar, insanları alternatif enerjiye teşvik etmektedir. Mısır ve soya fasulyesinden çıkarılan biyoetanol ve biyodizel, ham petrolün uygun ikamesi olarak kabul edilmektedir. Bu nedenle, petrol fiyatlarındaki artışlar mısır ve soya fasulyesi fiyatlarında artışa neden olabilmekte ve nihayetinde ekim alanlarının belirli bir zaman diliminde sınırlı olması nedeniyle diğer tarımsal emtia fiyatlarında artışlara yol açabilmektedir (Chang ve Su, 2010). Bunlara ek olarak, küresel gıda üretiminin artan maliyetleri göz önüne alındığında, gıda ithal eden ülkeler için artan petrol fiyatları gıda ithalat faturalarını yükseltecektir. Dolayısıyla bu durum yurt içi gıda fiyatları üzerinde yukarı yönlü bir baskı oluşturacaktır (Konandreas, 2012).

Döviz kurundaki dalgalanmaların da petrol fiyatlarına benzer şekilde gıda fiyatlarına girdi maliyetleri kanalından ve taşıma maliyetleri kanalından etki ettiği düşünülmektedir. 2008 ve 2011 yıllarında gıda fiyatlarındaki artış üzerine yapılan araştırmalar, ABD Doları (USD) oranının gıda fiyat hareketlerini açıklamada önemli bir etken olduğuna işaret etmektedir (Reboredo ve Ugando, 2014). Nazlıoğlu ve Soytaş (2012) çalışmalarında petrol fiyatları ile birlikte döviz kurunun tarımsal emtia fiyatları üzerindeki etkisine vurgu yapmışlardır. Döviz kuru hareketliliklerinin petrol ithalatı yüksek olan ülkelerde petrol ithalatı ödemelerinin döviz ile yapılmasından kaynaklı ekonomilere olumsuz etkisi mevcuttur. Döviz kuru değişimleri petrolde dışa bağımlılığı yüksek ekonomilerde petrol fiyatları kanalından gıda fiyatlarına etki etmektedir. Adil vd. (2021), 
çalışmalarında petrol fiyatları ile gıda fiyatları arasındaki ilişkide döviz kurunun aracılık rolüne vurgu yapmışlardır.

Enerjide dışa bağımlı özellikle de petrol konusunda dışa bağımlı ülkelerde petrol fiyatlarının gıda fiyatları üzerindeki etkisinin daha net olduğu düşünülmektedir. Şöyle ki petrol ürünlerini ithal eden ülkeler hem petrol fiyatlarından hem de petrolü yabancı para cinsinden ithal ettiklerinden döviz kurundaki olumsuz etkilerden payını almaktadır. Bununla birlikte, petrol ürünlerini üreten ve ihraç eden ülkelerde ise enerji fiyatlarındaki veya döviz kurundaki artışların olumsuz etkisi görülmeyebilecektir. Hatta döviz kurundaki artışın dış ticareti olumlu etkilemesi söz konusu olabilecektir.

Bu açıklamalar çerçevesinde bu çalışmanın amacı petrol fiyatları ve döviz kurundaki değişimlerin gıda fiyatlarına bir etkisi olup olmadığını ve varsa bu etkinin asimetrik bir etki olup olmadığını araştırmaktır. Bu amaç çerçevesinde petrol fiyatlarının ve döviz kurunun gıda fiyatları üzerindeki etkileri Türkiye örneği üzerinden incelenmiştir. Türkiye' nin gelişmekte olan bir ekonomiye sahip olması, enerjide dışa bağımlılığının yüksek olması, döviz kuru hareketliliklerinin yüksek olduğu bir ülke konumunda olması gibi nedenlerden dolayı, petrol fiyatları ve döviz kuru şoklarının gıda fiyatları üzerindeki etkisini analiz etme noktasında Türkiye'nin önemli bir örnek oluşturacağı düşünülmektedir.

Çalışmanın bundan sonraki bölümlerinde ilk olarak literatür incelemesine yer verilmiştir. Daha sonra çalışmada kullanılan veri seti ve yöntem açıklanmıştır. Son olarak, analiz sonucu elde edilen ampirik bulgular verilmiş ve bu bulgular tartışılmıştır.

\section{Literatür}

Özellikle 1970'li yıllarda yaşanan tecrübelerden hareketle petrol şokları ve döviz kurunun gıda fiyatları üzerine etkilerinin incelendiği çalışmalar literatürde yer almaya başlamıştır. Literatür incelenirken konu iki grupta ele alınacaktır. Birincisi döviz kurlarının gıda fiyatlarına etkisinin incelendiği çalışmalar, ikincisi ise petrol fiyatlarının gıda fiyatlarına etkisinin incelendiği çalışmalar olacaktır. Ayrıca petrol fiyatlarının etkisini ele alan çalışmalar; tarımsal emtia fiyatları ve genel (küresel) gıda fiyatları üzerinden etkiyi ele alan çalışmalar olarak iki grupta incelenmiştir.

Döviz kurlarındaki değişikliklerin girdi maliyetleri üzerindeki doğrudan etkisi gıda fiyatlarına geçişkenliği artırmaktadır. Bu çerçevede literatürde bu etkiye yönelik çeşitli çalışmalar mevcuttur. Bu çalışmalara örnek olarak Reboredo ve Ugando (2014), Wong ve Shamsudin (2017) ve Katusiime (2018) verilebilir. Reboredo ve Ugando (2014) döviz kuru ile gıda (mısır, soya fasulyesi, buğday ve pirinç) fiyatları arasındaki ilişkiyi incelemişlerdir. Çalışmanın sonucunda sadece soya fasulyesi ile döviz kuru arasında bir ilişki tespit etmişlerdir. Wong ve Shamsudin (2017) Malezya için ham petrol fiyatlarının, döviz kurlarının ve reel GSYH'nın gıda fiyatı dalgalanmaları üzerine etkilerini incelemişlerdir. Çalışmada reel GSYH ve döviz kurlarının gıda fiyat hareketleri üzerinde asimetrik uzun vadeli bir etkisi tespit edildiğinden, politika yapıcıların ham petrol fiyatı yerine döviz kuru faktörünü dikkate almaları gerektiği ifade edilmektedir. Katusiime (2018) döviz kuru oynaklığının petrol ve gıda fiyatlarına etkisi incelemiştir. Çalışmanın bulguları, 2008 küresel finansal kriz sırasında ve sonrasında dinamik koşullu korelasyonların güçlendiğine işaret ederek, küresel finansal krizin ardından bu piyasalar arasındaki oynaklık yayılmalarında ve karşılıklı bağımlılıkta bir artış olduğunu göstermektedir.

Petrol fiyatlarının gıda fiyatları üzerine etkisi üzerine çalışmalar 2007 yılından sonra hızlanmıştır. Bunun nedeni 2007 ortalarından sonra gıda fiyatlarının hızla artması ve bunun nedeni olarak da aynı dönemde hızla artan petrol fiyatlarının görülmesidir. Ocak 2000 - Mart 2008 arası dönemde petrol fiyatları \%300'ün üzerinde artış kaydederken gıda fiyatları da \%107 oranında artmıştır (Arshad ve Hameed, 2009).

Petrol fiyatlarının gıda fiyatlarına etkisini inceleyen çalışmaların bir kısmı tarımsal emtia fiyatları üzerinden etkiyi ölçmektedir. Bu çalışmalara örnek olarak Arshad ve Hameed (2009), Chen vd. (2010), Nazlioglu ve Soytas (2012), Avalos (2014), Wang vd. (2014), Zhang ve Qu (2015), Olasunkanmi ve Oladele (2018) ve Roman vd. (2020) verilebilir. Arshad ve Hameed (2009) petrol fiyatından üç tahıl fiyatına; mısır, pirinç ve buğday arasında uzun vadeli tek yönlü bir nedensellik olduğunu tespit etmişlerdir. Chen vd. (2010) 
ham petrol fiyatı ile mısır, soya fasulyesi ve buğday için küresel tahıl fiyatları arasındaki ilişkileri inceledikleri çalışmalarında; her bir tahıl fiyatındaki değişimin, ham petrol fiyatlarındaki ve diğer tahıl fiyatlarındaki değişimlerden önemli ölçüde etkilendiği bulgusuna ulaşmışlardır. Nazlıoğlu ve Soytaş (2012) ise dünya petrol fiyatlarının çeşitli tarımsal emtia fiyatları üzerindeki rolüne güçlü bir destek bulunduğunu ve zayıf $A B D$ Dolarının tarım fiyatları üzerindeki olumlu etkisinin de teyit edildiğini belirtmişlerdir. Avalos (2014)'un ABD üzerine çalışmasının bulguları yapısal istikrarın reddedildiğini ve petrol fiyatı değişimlerinin mısır fiyatlarına aktarılmasının 2006 yııından sonra daha güçlü hale geldiğini göstermektedir. Aynı etki soya fasulyesi için geçerli değildir. Bir başka çalışmada Wang vd. (2014), petrol şoklarının 2006-2008 gıda krizinden önce tarımsal emtia fiyatlarındaki değişimin çok küçük bir kısmını açıklayabildiğini ancak kriz sonrası dönemde bunların açıklama yeteneklerinin çok daha yüksek hale geldiğini belirtmişlerdir. Zhang ve Qu (2015) ise küresel petrol fiyat şoklarının güçlü buğday, mısır, soya fasulyesi, fasulye küspesi, pamuk ve doğal kauçuk dahil olmak üzere Çin'deki tarımsal emtialar üzerindeki etkisini incelemişler ve petrol fiyatının volatilite kümelenmesi ve sıçrama davranışı ile karakterize edildiğini, aynı zamanda, petrol fiyat şoklarının tarımsal emtialar üzerinde farklı etkileri olduğunu tespit etmişlerdir. Olasunkanmi ve Oladele (2018), tarımsal emtia fiyatlarının artışında petrol fiyatı artışının önemli olması nedeniyle, çabaların petrol sektörünün yerel kalkınmasına yönelik olması gerektiğini, çünkü bu durumun tarım sektörü üzerinde olumlu yayılma etkisi yaratacağını ve uygun fiyatlarla gıdanın bulunmasını sağlayarak yaşam standardını ve refahı iyileştireceğini önermektedirler. Roman vd. (2020) petrol fiyatları ile gıda fiyatları arasındaki ilişkiyi ham petrol fiyatları ve çeşitli tarımsal emtia (süt ürünleri, et, yağlar, tahıllar ve şeker) fiyatlarını kullanarak incelemişlerdir. Çalışmanın sonucunda ham petrol fiyatları ile et fiyatları arasında uzun dönemli ilişki, gıda ve tahıl fiyatları ile ham petrol fiyatları arasında ise kısa dönemli ilişki tespit etmişlerdir.

Bir başka grup çalışmada ise petrol fiyatlarının gıda fiyatları üzerindeki etkisi genel gıda fiyatları üzerinden araştırılmıştır. Bu çalışmalara da örnek olarak Imai vd. (2008), Moss vd. (2010), Alghalith (2010), Pala (2013), Ibrahim (2015), Meyer vd. (2018), Wei Su vd. (2019), Adil vd. (2021) ve Karakotsios vd. (2021) verilebilir. Imai vd. (2008) petrol fiyatının tarımsal emtia fiyatları üzerinde önemli bir olumlu etkisi olduğunu, bununla birlikte, bazı durumlarda fiyat şoklarının kalıcı olduğunu bazılarında ise kısa ömürlü olduğunu belirtmişlerdir. Alghalith (2010) çalışmasında petrol fiyatındaki bir Dolarlık artışın gıda fiyat endeksinde yaklaşık 5,6 puanlık artışa neden olduğu sonucuna ulaşmıştır. Moss vd. (2010), 2004 ve 2007 yılları arasında enerji fiyatlarındaki artışın ABD'de toplam tarım için çeşitli potansiyel sonuçlarını araştırmışlar ve ABD'nin toplam tarımsal arz fonksiyonunun enerji fiyatlarına duyarlı olduğu sonucuna ulaşmışlardır. Pala (2013) yukarıdaki çalışmaların bulgularından farklı bir bulguya ulaşmıştır. Çalışmada bütün dönemler için petrol fiyatları ve gıda fiyatları arasında uzun dönemli ilişki tespit edildiği ancak 1990-2008 döneminde eşbütünleşme katsayısının negatif, 2008-2011 döneminde ise katsayının pozitif olduğu belirtilmektedir. Bu bulguların ham petrol ile gıda fiyatları arasındaki ilişkinin tesadüfen olduğunu gösterdiği ifade edilmiştir. Ibrahim (2015) uzun dönemde petrol fiyatı artışları ile gıda fiyatı arasında önemli bir ilişki bulunduğunu, ancak petrol fiyatlarındaki düşüşler ile gıda fiyatı arasında uzun dönemli ilişki bulunmadığını ifade etmiştir. Ayrıca, kısa dönemde, petrol fiyatındaki yalnızca pozitif değişiklikler gıda fiyatları enflasyonu üzerinde önemli etkiler yaratmaktadır. Meyer vd. (2018), 2001 ve 2014 yılları arasında petrol ihraç eden gelişmekte olan ülkelerde petrol fiyatlarındaki değişimlerin gıda fiyatları üzerindeki etkilerini incelemişlerdir. Çalışmanın sonucunda uzun dönemde petrol fiyatı artışları ile gıda fiyatları arasında önemli ve pozitif bir ilişki olduğu, öte yandan, petrol fiyatlarındaki düşüşler ile gıda fiyatları arasında uzun vadeli bir ilişki bulunmadığı bulgusuna ulaşıımıştır. Wei-Su vd. (2019)'nin çalışmalarındaki ampirik bulgular, belirli alt dönemlerde petrol ve tarım fiyatları arasında zamanla değişen pozitif çift yönlü nedenselliğin var olduğunu göstermektedir ve bu, enerji ve tarım fiyatlarının doğrudan biyoyakıt kanalı ve dolaylı girdi kanalıyla etkileşime girebileceği dikey pazar entegrasyon modelini desteklemektedir. Adil vd. (2021) Pakistan örneğinde, petrol fiyatlarının gıda fiyatları üzerindeki etkisini döviz kuru kanalından incelemişlerdir. Çalışmanın sonucunda döviz kurunun hem petrol fiyatları hem de gıda fiyatları üzerinde pozitif etkileri tespit edilmiştir. Ayrıca döviz kurunun petrol fiyatları ile gıda fiyatları arasındaki ilişkiye aracılık ettiği tespit edilmiştir. Karakotsios vd. (2021) ham petrol fiyatları ile küresel gıda fiyatları arasındaki etkileşimi incelemişler ve petrolden gıda fiyatlarına uzanan tek yönlü bir nedensel ilişki tespit etmişlerdir. 


\section{Veri Seti ve Yöntem}

Çalışmada kullanılan model literatürdeki Wong ve Shamsudin (2017) ve Meyer vd. (2018) gibi çalışmalar örnek alınarak tasarlanmıştır.

$$
F P_{t}=\alpha_{0}+\alpha_{1} O P_{t}+\alpha_{2} E P_{t}+\alpha_{3} E X R_{t}+\alpha_{4} I P I_{t}+u_{t}
$$

(1) no'lu modelde FP değişkeni gıda fiyatlarını, OP değişkeni petrol fiyatlarını, EP değişkeni genel enerji fiyatlarını, EXR değişkeni döviz kurunu ve IPI değişkeni sanayi üretim endeksini ifade etmektedir. Çalışmada 2010 Ocak - 2019 Aralık dönemi için aylık veriler kullanılmıştır. EP ve IPI değişkenleri kontrol değişkenlerdir. Veri seti aylık olduğundan ekonomik büyüme rakamları kullanılamamış ve ekonomik büyümeyi temsil yeteneği yüksek olan sanayi üretim endeksi kullanılmıştır. FP değişkeni TÜFE içerisinde gıda ve alkolsüz içecekler grubunu, EP değişkeni özel kapsamlı TÜFE göstergeleri içinde enerji grubunu ve IPI değişkeni mevsim ve takvim etkilerinden arındırılmış sanayi üretim endeksini ifade etmekte olup, üç değişken de TÜik'ten sağlanmıştır. OP değişkeni Brent petrol fiyatlarını ve EXR değişkeni nominal ABD Doları/TL kurunu göstermekte olup, TCMB'den sağlanmıştır.

Çalışmada petrol fiyatları ve döviz kurunun gıda fiyatları üzerine etkisini incelemek amacıyla Shin vd. (2014) tarafından geliştirilen NARDL (Doğrusal Olmayan Otoregresif Dağııılmış Gecikme) yöntemi uygulanmıştır. NARDL yöntemi, Pesaran vd. (2001) tarafından geliştirilen ARDL yönteminin kısa ve uzun dönem asimetrik ilişkileri içerecek şekilde değiştirilmiş versiyonudur. NARDL yöntemi ARDL yöntemindekine benzer şekilde serilerin durağan olma ya da aynı dereceden durağan olma şartı taşımamaktadır. Bu yöntemde serilerin ikinci dereceden durağan olmaması gerekmektedir (Akçay, 2021).

Çalışmada petrol fiyatları ve döviz kurunun asimetrik etkisini incelemek amacıyla kullanılan NARDL modeli eşitlik (2)'deki gibi gösterilebilir:

$$
\begin{aligned}
& F P_{t}=\alpha_{0}+\alpha_{1} O P_{t}^{+}+\alpha_{2} O P_{t}^{-}+\alpha_{3} E P_{t}^{+}+\alpha_{4} E P_{t}^{-}+\alpha_{5} E X R_{t}^{+}+\alpha_{6} E X R_{t}^{-}+\alpha_{7} I P I_{t}^{+}+ \\
& \alpha_{8} I P I_{t}^{-}+u_{t}
\end{aligned}
$$

(2) no'lu eşitlikteki $O P_{t}^{+}$ve $O P_{t}^{-}$petrol fiyatlarının, $E P_{t}^{+}$ve $E P_{t}^{-}$enerji fiyatlarının, $E X R_{t}^{+}$ve $E X R_{t}^{-}$ döviz kurunun ve $I P I_{t}^{+}$ve $I P I_{t}^{-}$sanayi üretim endeksinin pozitif ve negatif değişimlerinin kümülatif toplamını ifade etmektedir ve aşağıdaki gibi gösterilebilir:

$$
\begin{aligned}
& O P_{t}^{+}=\sum_{j=1}^{t} \Delta O P_{j}^{+}=\sum_{j=1}^{t} \max \left(\Delta O P_{j}, 0\right), O P_{t}^{-}=\sum_{j=1}^{t} \Delta O P_{j}^{-}=\sum_{j=1}^{t} \min \left(\Delta O P_{j}, 0\right) \\
& E P_{t}^{+}=\sum_{j=1}^{t} \Delta E P_{j}^{+}=\sum_{j=1}^{t} \max \left(\Delta E P_{j}, 0\right), E P_{t}^{-}=\sum_{j=1}^{t} \Delta E P_{j}^{-}=\sum_{j=1}^{t} \min \left(\Delta E P_{j}, 0\right) \\
& E X R_{t}^{+}=\sum_{j=1}^{t} \Delta E X R_{j}^{+}=\sum_{j=1}^{t} \max \left(\Delta E X R_{j}, 0\right), E X R_{t}^{-}=\sum_{j=1}^{t} \Delta E X R_{j}^{-}=\sum_{j=1}^{t} \min \left(\Delta E X R_{j}, 0\right) \\
& I P I_{t}^{+}=\sum_{j=1}^{t} \Delta I P I_{j}^{+}=\sum_{j=1}^{t} \max \left(\Delta I P I_{j}, 0\right), I P I_{t}^{-}=\sum_{j=1}^{t} \Delta I P I_{j}^{-}=\sum_{j=1}^{t} \min \left(\Delta I P I_{j}, 0\right)
\end{aligned}
$$

Shin vd. (2014)'nin geliştirdiği NARDL modelinin bu çalışma için kullanılan versiyonuna (3), (4), (5) ve (6) eşitliklerde yer alan değişkenlerin pozitif ve negatif değişimlerinin kümülatif toplamları (2) no'lu eşitlikte yer alan modele eklendiğinde aşağıdaki gibi elde edilebilir:

$$
\begin{aligned}
& \Delta F P_{t}=\alpha_{0}+\alpha_{1} F P_{t-1}+\alpha_{2}^{+} O P_{t}^{+}+\alpha_{3}^{-} O P_{t}^{-}+\alpha_{4}^{+} E P_{t}^{+}+\alpha_{5}^{-} E P_{t}^{-}+\alpha_{6}^{+} E X R_{t}^{+}+\alpha_{7}^{-} E X R_{t}^{-}+ \\
& \alpha_{8}^{+} I P I_{t}^{+}+\alpha_{9}^{-} I P I_{t}^{-}+\sum_{i=1}^{k} \beta_{0 i} \Delta F P_{t-i}+\sum_{i=0}^{l}\left(\beta_{1}^{+} \Delta O P_{t-i}^{+}+\beta_{1}^{-} \Delta O P_{t-i}^{-}\right)+\sum_{i=0}^{m}\left(\beta_{2}^{+} \Delta E P_{t-i}^{+}+\right. \\
& \left.\beta_{2}^{-} \Delta E P_{t-i}^{-}\right)+\sum_{i=0}^{n}\left(\beta_{3}^{+} \Delta E X R_{t-i}^{+}+\beta_{3}^{-} \Delta E X R_{t-i}^{-}\right)+\sum_{i=0}^{p}\left(\beta_{4}^{+} \Delta I P I_{t-i}^{+}+\beta_{4}^{-} \Delta I P I_{t-i}^{-}\right)+u_{t}
\end{aligned}
$$


(7) no'lu eşitlikte k, I, m, n ve p gecikme uzunluklarını göstermektedir. Pesaran vd. (2001) ve Shin vd. (2014) önerdikleri ARDL ve NARDL modellerinde I(0) ve I(1) değişkenler ile eşbütünleşme incelenebileceğini belirtmişlerse de serilerin I(2) olmadığını kanıtlamak için öncelikle birim kök testi yapılır. Birim kök testinden sonra değişkenler arasında eşbütünleşme olup olmadığının araştırılması için eşbütünleşme testi yapılır. Pesaran (2001) tarafından önerilen yöntemde eşbütünleşmenin olmadığına dair boş hipotezi $\left(H_{0}: \alpha_{1}=\cdots=\right.$ $\alpha_{9}$ ) ile eşbütünleşmenin olduğuna dair alternatif hipotez $\left(H_{1}: \alpha_{1} \neq \cdots \neq \alpha_{9}\right) \mathrm{F}$ testi ile kritik değerler (alt sınır ve üst sınır) karşılaştırılarak belirlenir. (7) no'lu eşitlikte petrol fiyatlarının uzun dönem asimetrik etkisi Wald testi kullanılarak $\left(\alpha_{2}^{+}=\alpha_{3}^{-}\right)$boş hipotezi kullanılarak test edilebilir. Benzer şekilde enerji fiyatlarının uzun dönem asimetrik etkisi $\left(\alpha_{4}^{+}=\alpha_{5}^{-}\right)$boş hipotezi, döviz kurunun uzun dönem asimetrik etkisi $\left(\alpha_{6}^{+}=\alpha_{7}^{-}\right)$boş hipotezi ve sanayi üretim endeksinin uzun dönem asimetrik etkisi $\left(\alpha_{8}^{+}=\alpha_{9}^{-}\right)$boş hipotezi kullanılarak test edilebilir. $O P_{t}^{+}$ve $O P_{t}^{-}$için normalize edilen uzun dönem katsayıları ise $\gamma^{+}=-\left(\frac{\alpha_{2}^{+}}{\alpha_{1}}\right), \gamma^{-}=-\left(\frac{\alpha_{3}^{-}}{\alpha_{1}}\right)$ şeklinde hesaplanabilir. Benzer olarak $E P_{t}^{+}$ve $E P_{t}^{-}$için $\mu^{+}=-\left(\frac{\alpha_{4}^{+}}{\alpha_{1}}\right), \mu^{-}=-\left(\frac{\alpha_{5}^{-}}{\alpha_{1}}\right)$ şeklinde, $E X R_{t}^{+}$ve $E X R_{t}^{-}$için $\theta^{+}=$ $-\left(\frac{\alpha_{6}^{+}}{\alpha_{1}}\right), \theta^{-}=-\left(\frac{\alpha_{7}^{-}}{\alpha_{1}}\right)$ ve IPI $I_{t}^{+}$ve IPI $I_{t}^{-}$için $\vartheta^{+}=-\left(\frac{\alpha_{8}^{+}}{\alpha_{1}}\right), \vartheta^{-}=-\left(\frac{\alpha_{9}^{-}}{\alpha_{1}}\right)$ şeklinde hesaplanabilir. Kısa dönem asimetrik etki yine Wald testi yardımıyla petrol fiyatları için $\left(\beta_{1}^{+}=\beta_{1}^{-}\right)$boş hipoteziyle, enerji fiyatları için $\left(\beta_{2}^{+}=\beta_{2}^{-}\right)$boş hipoteziyle, döviz kuru için $\left(\beta_{3}^{+}=\beta_{3}^{-}\right)$boş hipoteziyle ve sanayi üretim endeksi için $\left(\beta_{4}^{+}=\right.$ $\beta_{4}^{-}$) boş hipoteziyle hesaplanabilir.

Ayrıca modelde $O P_{t}^{+}$ve $O P_{t}^{-`}$ nin bağımlı değişken üzerindeki asimetrik kümülatif dinamik çarpan (cumulative dynamic multiplier) etkisi aşağıdaki gibi tanımlanabilir:

$$
m_{h}^{+}=\sum_{j=0}^{h} \frac{\partial F P_{t+j}}{\partial O P_{t}^{+}}=\sum_{j=0}^{h} \lambda_{j}^{+}, m_{h}^{-}=\sum_{j=0}^{h} \frac{\partial F P_{t+j}}{\partial O P_{t}^{-}}=\sum_{j=0}^{h} \lambda_{j}^{-}, h=0,1,2, \ldots
$$

Diğer asimetrik kümülatif dinamik çarpan etkileri de (8) no'lu eşitlikteki gibi benzer şekilde tanımlanabilir.

\section{Ampirik Bulgular}

Tablo 1 çalışmada kullanılan değişkenlerin birim kök testi sonuçlarını göstermektedir. Birim kök tespiti amacıyla Dickey ve Fuller (1981) tarafından geliştirilen ADF birim kök testi ile birlikte Philips ve Perron (1988) tarafından geliştirilen PP birim kök testi kullanılmıştır. Birim kök testi sonuçlarına göre bağımlı ve bağımsız değişkenlerin tamamı birinci farklarında durağandır. Her iki birim kök testi sonuçları onaylamaktadır. NARDL yönteminin varsayımlarından biri olan değişkenlerin ikinci dereceden durağan olmaması şartı gerçekleşmiştir.

Tablo 1. Birim Kök Testleri

\begin{tabular}{lcccccc}
\hline \multirow{2}{*}{ Değişken } & \multicolumn{3}{c}{ ADF } & \multicolumn{3}{c}{ PP } \\
\cline { 2 - 6 } & Sabit & Sabit\&Trend & Birinci Fark & Sabit & Sabit\&Trend & Birinci Fark \\
\hline FP & $1,87(0,99)$ & $-1,55(0,80)$ & $-4,65(0,00)^{* * *}$ & $1,64(0,99)$ & $-1,07(0,93)$ & $-8,50(0,00)^{* * *}$ \\
OP & $-1,54(0,51)$ & $-2,24(0,46)$ & $-8,73(0,00)^{* * *}$ & $-1,40(0,58)$ & $-2,19(0,49)$ & $-8,58(0,00)^{* * *}$ \\
EP & $1,42(0,99)$ & $-0,55(0,98)$ & $-7,21(0,00)^{* * *}$ & $2,35(1,00)$ & $0,13(0,99)$ & $-6,48(0,00)^{* * *}$ \\
EXR & $1,04(0,99)$ & $-1,47(0,83)$ & $-9,25(0,00)^{* * *}$ & $0,78(0,99)$ & $-1,71(0,74)$ & $-7,01(0,00)^{* * *}$ \\
IPI & $-1,88(0,34)$ & $-2,65(0,25)$ & $-17,73(0,00)^{* * *}$ & $-1,84(0,36)$ & $2,09(0,99)$ & $-18,05(0,00)^{* * *}$ \\
\hline
\end{tabular}

Parantez içindeki değerler olasılık değerlerini yansıtır. ADF testi için gecikme uzunluğu Schwarz, PP testi için NeweyWest Bandwidth bilgi kriterlerinden yararlanılmıştır. ${ }^{* * *},{ }^{* *},{ }^{*}$ sırasıyla $\% 1, \% 5$ ve $\% 10$ düzeyinde istatistiksel anlamlılığı göstermektedir. 
Tablo 2 değişkenler arasında uzun dönem ilişkisi olup olmadığını, bir diğer deyişle, eşbütünleşme olup olmadığının araştırııması amacıyla sınır testi sonuçlarını göstermektedir. Değişkenler arasında eşbütünleşme olup olmadığı çeşitli güven aralıklarında verilen kritik değerler ile $\mathrm{F}$ istatistiğinin karşılaştırılması sonucu belirlenmektedir. $\mathrm{F}$ istatistiği > kritik değer ise $\mathrm{H}_{0}$ (boş hipotez) ret edilir ve eşbütünleşme (uzun dönem ilişki) olduğu sonucuna ulaşılır. Tablo da görüleceği üzere $\mathrm{F}$ istatistiği \%1 güven aralığında dahi kritik değerlerden büyüktür. Bu durum kurulan modeldeki değişkenler arasında eşbütünleşme olduğunu göstermektedir.

Tablo 2. NARDL Asimetrik Eşbütünleşme (Bounds) Testi

\begin{tabular}{cccc}
\hline F İstatistiği & Güven Aralığı & Alt Sınır & Üst Sınır \\
\hline 9,710610 & $\% 10$ & 1,95 & 3,06 \\
& $\% 5$ & 2,22 & 3,39 \\
& $\% 1$ & 2,79 & 4,1 \\
\hline
\end{tabular}

Not: Kritik değerler Pesaran, Shin, and Smith (2001)'in çalışmasından elde edilmiştir.

Tablo 3'te ise NARDL yönteminin tahmin sonuçları yer almaktadır. Sonuçlar dört grupta ele alınmıştır. Illk olarak kısa dönem katsayılarına yer verilmiştir. Kısa dönem katsayılarından istatistiksel olarak anlamlı olmayan katsayılar tabloda yer almamaktadır. Sonuçlar petrol fiyatları ve döviz kuru değişkenlerinin katsayılarının çeşitli gecikmelerde anlamlı etkileri olduğunu göstermektedir. Kontrol değişkenler olan genel enerji fiyatları ve sanayi üretim endeksi değişkenleri katsayılarında da çeşitli gecikmelerde anlamlı etkiler görülmektedir. Tablo 3'ün A kısmında HDT olarak yer alan katsayı hata düzeltme terimidir. Hata düzeltme terimi negatif ve istatistiksel olarak anlamlıdır. Bu durum hata düzeltme mekanizmasının çalıştığını göstermektedir. Modelde kısa dönemde dengeden sapmalar uzun dönemde tekrar dengeye ulaşmaktadır. Katsayı ne kadar büyük olursa dengeye dönüş hızı da o kadar yüksek olacaktır.

NARDL modelinden elde edilen uzun dönem katsayıları normalize edilmiş katsayılar olarak adlandırılmaktadır (Turan ve Karakaş, 2018). Tablo 3'ün ikinci kısmında normalize edilmiş uzun dönem katsayıları yer almaktadır. Katsayılar incelendiğinde, hem petrol fiyatlarının hem de döviz kurunun pozitif değişimlerinin istatistiksel olarak anlamlı olduğu görülmektedir. Petrol fiyatları ve döviz kuru değişkenlerinin negatif şokları ise istatistiksel olarak anlamlı değildir. Yani pozitif ve negatif şoklar birbirinden ayrışmaktadır. $\mathrm{OP}^{+}$ve EXR $\% 1$ anlamlıık düzeyinde istatistiksel olarak anlamlıdır ve katsayılar pozitiftir. OP ve EXR'deki pozitif değişimler gıda fiyatlarını aynı yönde etkilemektedir. Petrol fiyatları 1 Dolar artığında gıda fiyat endeksi 0,30 birim, Dolar kuru 1 TL arttığında ise gıda fiyat endeksi 16,6 birim artmaktadır. Dolayısıyla döviz kurundaki pozitif şokların gıda fiyatları üzerindeki etkisinin daha büyük olduğu söylenebilir. Ayrıca petrol fiyatları ve döviz kurundaki negatif şokların anlamlı olmaması Türkiye'de gıda fiyatlarında aşağı yönlü bir katılık (rijitlik) olduğunu göstermektedir. $W_{L R}$ sonuçları çalışmada kullanılan bütün değişkenlerin uzun dönem asimetrik etkiye sahip olduğunu göstermektedir. Yani petrol fiyatları, döviz kuru, enerji fiyatları ve sanayi üretim endeksi uzun dönemde gıda fiyatları üzerinde asimetrik etkiye sahiptir.

Tablo 3'ün üçüncü kısmında yer alan asimetri testleri ise Wald testi yardımıyla uzun dönem ve kısa dönem asimetrik ilişkinin var olup olmadığını tespit etmeye yöneliktir. Sonuçlara göre petrol fiyatları ile gıda fiyatları arasında uzun dönemde asimetrik bir ilişki mevcut iken, kısa dönemde ilişki asimetrik değil simetriktir. Bu durum Altıntaş (2016)'ın çalışmasındaki petrol fiyatları ile gıda fiyatları arasında hem kısa hem de uzun dönemde asimetrik etki olduğuna yönelik sonuçlarla örtüşmemektedir. Ayrıca döviz kuru ile gıda fiyatları arasında da uzun dönem asimetrik ilişki tespit edilmiştir. Fakat kısa dönem asimetrik ilişki tespit edilememiş, ilişkinin simetrik olduğu sonucuna varılmıştır. Kontrol değişkenler enerji fiyatları ve sanayi üretim endeksi ile de gıda fiyatları ile sadece uzun dönem asimetrik ilişki tespit edilmiştir. 
Petrol Fiyatı ve Döviz Kurunun Gıda Fiyatları Üzerine Asimetrik Etkisi: Türkiye Örneği

Tablo 3. Tahmin Sonuçları

\begin{tabular}{|c|c|c|c|}
\hline \multicolumn{4}{|c|}{ NARDL Modeli $(4,3,1,3,3,3,4,4,2)$} \\
\hline \multicolumn{4}{|c|}{ A) Tahmin Sonuçları } \\
\hline & Katsayılar & t-istatistiği & Olasılık \\
\hline C & $144,8576 * * *$ & 8,105747 & 0,0000 \\
\hline $\mathrm{FP}(-1)$ & $-0,774264 * * *$ & $-8,010938$ & 0,0000 \\
\hline $\mathrm{OP}^{+}(-1)$ & $0,236641 * * *$ & 3,000507 & 0,0036 \\
\hline$E P^{+}(-1)$ & $0,261460 * * *$ & 3,205906 & 0,0019 \\
\hline$E P^{-}(-1)$ & $-0,649303 * *$ & $-2,017804$ & 0,0470 \\
\hline $\operatorname{EXR}^{+}(-1)$ & $12,88473 * * *$ & 2,852597 & 0,0055 \\
\hline $\mathrm{IPI}^{+}(-1)$ & $0,681893 * * *$ & 3,294922 & 0,0015 \\
\hline$\Delta \mathrm{FP}(-1)$ & $0,561036 * * *$ & 5,653903 & 0,0000 \\
\hline$\triangle \mathrm{FP}(-3)$ & $0,648257 * * *$ & 6,464079 & 0,0000 \\
\hline$\Delta \mathrm{OP}^{+}(-1)$ & $0,319696 * *$ & 2,101686 & 0,0388 \\
\hline$\Delta \mathrm{OP}^{+}(-2)$ & $0,329185^{* *}$ & 2,210850 & 0,0299 \\
\hline$\Delta E P^{+}(-1)$ & $-0,450848^{* *}$ & $-2,410486$ & 0,0183 \\
\hline$\Delta \mathrm{EP}-(-1)$ & $0,954193^{* *}$ & 2,527670 & 0,0135 \\
\hline$\Delta \mathrm{EP}^{-}(-2)$ & $-0,833289 * * *$ & $-2,818464$ & 0,0061 \\
\hline$\Delta \mathrm{EXR}^{+}$ & $16,76122 * * *$ & 2,874294 & 0,0052 \\
\hline$\Delta \operatorname{EXR}^{+}(-2)$ & $19,20254^{* *}$ & 2,158150 & 0,0340 \\
\hline$\triangle$ EXR- $^{-}$ & $29,77218^{* *}$ & 2,080090 & 0,0408 \\
\hline$\Delta \operatorname{EXR}^{-}(-3)$ & $-33,37131 * * *$ & $-2,887683$ & 0,0050 \\
\hline$\Delta \mathrm{IPI}^{+}$ & $-1,229641 * *$ & $-2,481783$ & 0,0152 \\
\hline$\Delta \mathrm{IPI}^{+}(-2)$ & $-1,127435^{* * *}$ & $-2,785330$ & 0,0067 \\
\hline$\Delta \mathrm{IPI}^{+}(-3)$ & $-0,621311^{*}$ & $-1,695918$ & 0,0938 \\
\hline$\Delta \mathrm{IPI}^{-}(-1)$ & $-1,934502 * * *$ & $-2,868757$ & 0,0053 \\
\hline HDT(-1) & $-0,774264 * * *$ & $-9,810487$ & 0,0000 \\
\hline B) Uzun & & & \\
\hline & Katsayılar & t-istatistiği & Olasılık \\
\hline $\mathrm{OP}^{+}$ & $0,305633^{* * *}$ & 2,763607 & 0,0071 \\
\hline OP- & 0,034003 & 0,374665 & 0,7089 \\
\hline $\mathrm{EP}^{+}$ & $0,337688 * * *$ & 2,994611 & 0,0037 \\
\hline EP- & $-0,838607 * *$ & $-2,198085$ & 0,0309 \\
\hline $\mathrm{EXR}^{+}$ & $16,64127^{* * *}$ & 3,338211 & 0,0013 \\
\hline EXR- $^{-}$ & $-1,278775$ & $-0,096853$ & 0,9231 \\
\hline $\mathrm{IPI}^{+}$ & $0,880699 * * *$ & 3,346221 & 0,0013 \\
\hline $\mathrm{IPI}^{-}$ & 0,106978 & 0,230090 & 0,8186 \\
\hline Asime & & & \\
\hline & $W_{L R}$ & $W_{S R}$ & \\
\hline $\mathrm{OP}$ & $9,11^{* * *}(0,004)$ & $0,30(0,581)$ & \\
\hline EP & $3,92 *(0,052)$ & $0,01(0,912)$ & \\
\hline EXR & $4,23 * *(0,043)$ & $2,43(0,123)$ & \\
\hline IPI & $3,19 *(0,078)$ & $0,55(0,459)$ & \\
\hline D) Tanisc & & & \\
\hline & & F-istatistiği & Olasılık \\
\hline Breusch-Go & asyon LM Testi & 0,727 & 0,486 \\
\hline Jarque-Ber & & 0,364 & 0,833 \\
\hline ARCH Değiş & & 0,860 & 0,589 \\
\hline Ramsey Res & & 0,012 & 0,909 \\
\hline$R^{2}$ & 0,998 & Düzeltilmiş $R^{2}$ & 0,997 \\
\hline F-istatistiği & $1504,05^{* * *}(0,00)$ & DW & 2,033 \\
\hline $\begin{array}{l}\text { Not: }{ }^{* * *},{ }^{* *} \\
\text { içerisindeki } \\
\text { değişimlerir } \\
\text { göstermekt } \\
\text { kriteri kullar }\end{array}$ & $\begin{array}{l}\mathrm{L}, \% 5 \text { ve } \% 10 \text { düzey } \\
\mathrm{k} \text { değerlerini göstern } \\
\text { dir. } W_{L R} \text { ve } W_{S R} \text {, sıra } \\
\text { NARDL modeli için u }\end{array}$ & $\begin{array}{l}\text { tiksel anlamlılı̨̧ } \\
\text { e - ilgili değişk€ } \\
\text { e kısa vadede } \\
\text { ee sayısının tesp }\end{array}$ & $\begin{array}{l}\text { tedir. Pa } \\
\text { negatif } \\
\text { Wald te } \\
\text { kaike (AI }\end{array}$ \\
\hline
\end{tabular}


Çalışmanın ampirik bulgularına göre, petrol fiyatları ve döviz kurundaki değişimlerin gıda fiyatları üzerindeki etkisinin kısa dönemde simetrik olması, petrol fiyatları ve döviz kurlarındaki artış ve azalış yönündeki şokların gıda fiyatları üzerindeki etkisinin derecesinin aynı olduğu anlamına gelmektedir. Uzun dönemde ise bu şokların etkisinin derecesi farklılaşmaktadır. Bu durumun temel nedeninin tarım sektöründeki gecikme etkisi olduğu düşünülmektedir.

Tablo 3'ün son kısmında tanısal testler yer almaktadır. Sonuçlara göre modelde otokorelasyon ve değişen varyans sorunu bulunmamaktadır. Modeldeki değişkenler normal dağılmaktadır ve model kurma hatası bulunmamaktadır.

Grafik 1'de yer alan CUSUM ve CUSUMQ grafiklerinde NARDL modelinin katsayılarının istikrarlı (stabil) olduğu görülmektedir.

Grafik 1. Yapısal Kırılma Grafikleri (CUSUM ve CUSUMQ)
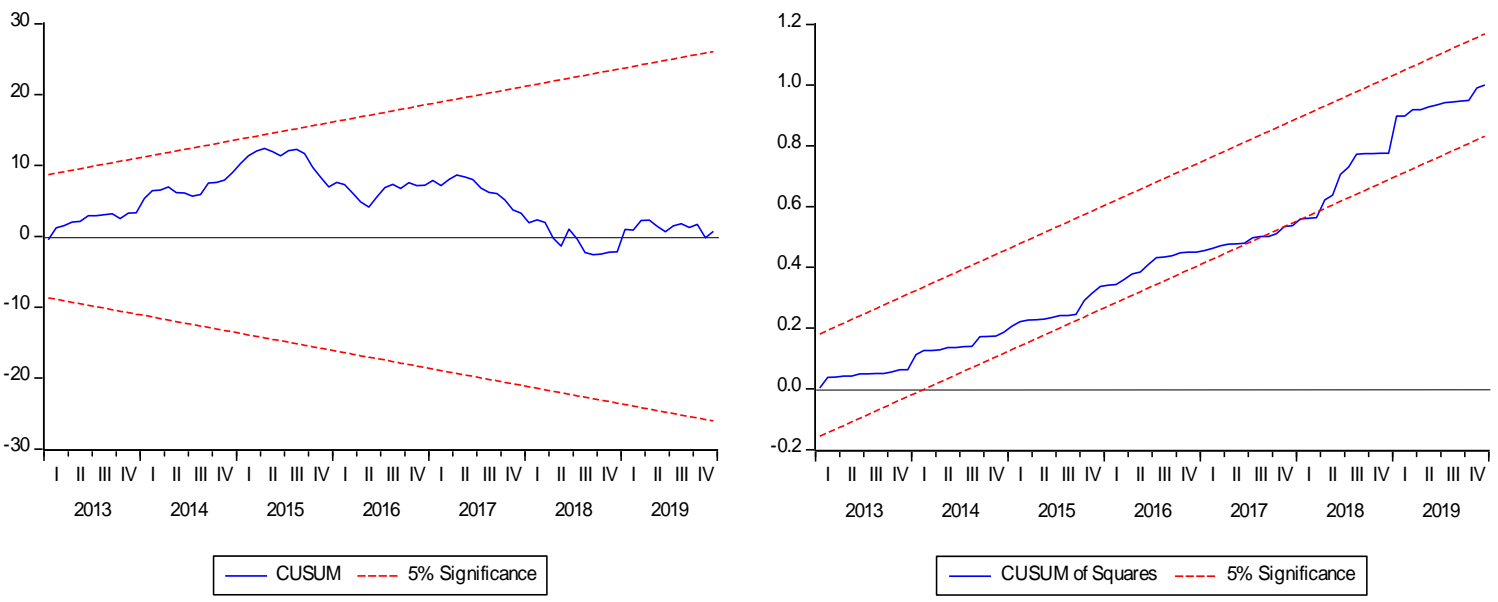

Grafik 2 asimetrik etkileri gösteren dinamik çarpan grafiklerini içermektedir. Soldaki grafik petrol fiyatlarının gıda fiyatlarına asimetrik etkisini, sağdaki grafik ise döviz kurunun gıda fiyatlarına asimetrik etkisini içermektedir. Dinamik çarpan grafikleri eşitlik (8)'e göre elde edilmiştir. Dinamik çarpan grafikleri açıklayıcı değişkenlerdeki pozitif ve negatif şoklara gıda fiyatlarının verdiği tepkileri göstermektedir. Siyah (düz) çizgi gıda fiyatlarının açıklayıcı değişkenlerdeki pozitif şoklara verdiği tepkiyi, siyah (az kesikli) çizgi gıda fiyatlarının açıklayıcı değişkenlerdeki negatif şoklara verdiği tepkiyi ve siyah (çok kesikli) çizgi ise gıda fiyatlarının pozitif ve negatif şoklara verdiği tepkinin farkı olarak ifade edilmekte ve asimetrileri göstermektedir. Asimetriler \%95 güven aralığında sunulmuştur.

Grafik 2. Dinamik Çarpan Grafikleri
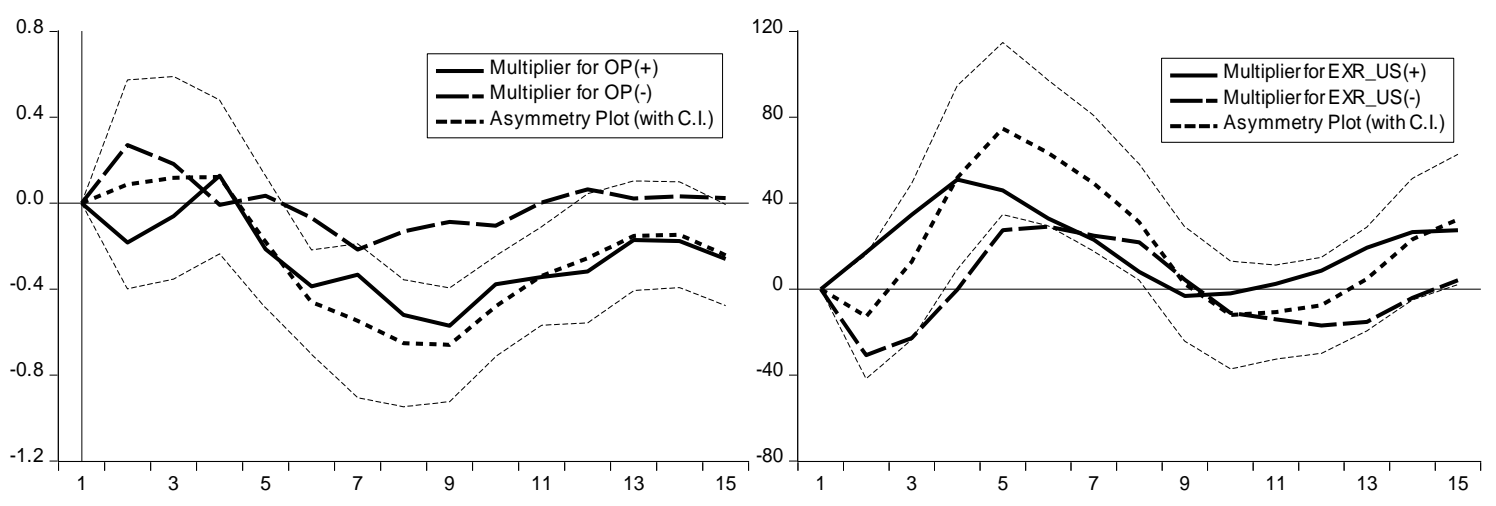
Grafik 2'de soldaki grafik petrol fiyatları şoklarının gıda fiyatları üzerindeki asimetrik etkisini içermektedir. İlk 3 ay pozitif şokların negatif etki bıraktığını, negatif şokların ise pozitif etki yaptığı görülmektedir. Ancak daha sonra hem pozitif hem de negatif şokların negatif asimetrik etki yaptığı tespit edilmiştir. Sağdaki grafik ise benzer şekilde döviz kurlarındaki şokların gıda fiyatları üzerindeki asimetrik etkilerini içermektedir. Döviz kurundaki pozitif şokların grafik neredeyse tamamında gıda fiyatlarına pozitif asimetrik etki yaptığı görülürken, negatif şokların ilk başta belli bir süre negatif, daha sonra belli bir süre pozitif ve son olarak yine belli bir süre pozitif asimetrik etki yaptığı görülmektedir. Net asimetri etkisi ise grafik boyunca genellikle pozitiftir.

\section{Sonuç}

Çalışma, Türkiye'de petrol fiyatları ve döviz kurlarının gıda fiyatları üzerindeki etkilerini araştırmaktadır. Bu etkinin literatürdeki (örneğin; Alghalith, 2010; Imai vd., 2008; Moss vd., 2010; Pala, 2013; Wei Su vd., 2019) çalışmalarda yer aldığı gibi doğrusal değil asimetrik olduğu düşünüldüğünden asimetrik etkileri ölçmek amacıyla NARDL yöntemi kullanıımıştır. Çalışmada kullanılan değişkenlere yönelik veriler Ocak 2010-Aralık 2019 dönemini kapsamaktadır. Çalışma petrol fiyatları ve döviz kurunun gıda fiyatları üzerindeki asimetrik etkilerine odaklanmıştır, ancak bununla birlikte modelde kontrol değişkeni olarak genel enerji fiyatları ve sanayi üretim endeksi de kullanılmıştır.

NARDL yöntemi çalışmada ele alınan petrol fiyatları ve döviz kurlarındaki değişimleri pozitif değişimler ve negatif değişimler olarak ayrıştırdığından, bu değişkenlerdeki pozitif ve negatif değişimlerin gıda fiyatlarına etkisi ayrı ayrı ele alınabilmiştir. Çalışmada kullanılan NARDL yönteminin sonuçları incelendiğinde hem petrol fiyatları şoklarının hem de döviz kuru şoklarının gıda fiyatları ile uzun dönem asimetrik ilişki içerisinde olduğu, ancak kısa dönem asimetrik ilişki bulunmadığı tespit edilmiştir. Eşbütünleşme testi sonucunda ise, bağımlı değişken ile açıklayıcı değişkenler arasında uzun dönemli ilişki tespit edilmiştir.

Bu bulgular çerçevesinde bu çalışmanın özgün değeri; petrol fiyatları ve döviz kurunun gıda fiyatları üzerindeki asimetrik etkisinin belirgin şekilde tespit edildiği çalışmalardan biri olmasıdır. Çalışmanın bulguları, Türkiye gibi gelişmekte olan ve yüksek enflasyon sorunu ile karşı karşıya olan bir ekonomi için oldukça önemli görülmektedir. Politika yapıcılar açısından enflasyonun belirleyicilerinden olan gıda fiyatları değerlendirilirken, petrol fiyatları ve döviz kurunun asimetrik etkisinin dikkate alınması gerekliliği çalışmanın ampirik bulguları ile ortaya konulmuştur. Dikkat edilmesi gereken bir diğer önemli husus ise gıda fiyatlarının negatif petrol fiyatları şokları ve negatif döviz kuru şoklarına tepkisinin zayıf olduğu gerçeğidir. Bu bağlamda petrol fiyatlarının ve döviz kurlarının pozitif şoklarının gıda fiyatlarına geçişkenliğini azaltacak tedbirlerin alınması önem kazanmaktadır.

\section{Beyan ve Açıklamalar (Declarations and Disclosures)}

Yazarların Etik Sorumlulukları (Ethical Responsibilities of Authors): Bu çalışmanın yazarı, araştırma ve yayın etiği ilkelerine uyduğunu kabul etmektedir.

Çıkar Çatışması (Conflicts of Interest): Yazar tarafından herhangi bir çıkar çatışması beyan edilmemiştir.

Finansal Destek (Funding): Yazar, çalışmanın hazırlanması ve/veya yayınlanması sürecinde herhangi bir finansal destek almamıştır.

Yazar Katkı Oranı (Author Contributions): Yazar; kavramlaştırma ve çalışma dizaynı, verilerin toplanması, verilerin analizi ve sonuçların yorumlanması, çalışmanın ilk/taslak halinin yazılması, çalışmanın gözden geçirilmesi ve düzenlenmesi/düzeltilmesi aşamalarından tek başına sorumlu olduğunu beyan etmektedir.

intihal Denetimi (Plagiarism Checking): Bu çalışma, intihal tarama programı kullanılarak intihal taramasından geçirilmiştir. 


\section{Kaynaklar}

Adil, S., Bhatti, A. A., Waqar, S., \& Amin, S. (2021). Unleashing the indirect influence of oil prices on food prices via exchange rate: New evidence from Pakistan. Journal of Public Affairs, 2615.

Akçay, S. (2021). Are oil prices and remittance outflows asymmetric? Evidence from Saudi Arabia. Energy Research Letters, 2(1), 1-5.

Alghalith, M. (2010). The interaction between food prices and oil prices. Energy Economics, 32(6), 1520-1522.

Altıntaş, H. (2016). Petrol fiyatlarının gıda fiyatlarına asimetrik etkisi: Türkiye için NARDL modeli uygulaması. Yönetim ve Ekonomi Araştırmaları Dergisi, 14(4), 1-24.

Alvarez, L., Hurtado, S., Sanchez, I., \& Thomas, C. (2011). The impact of oil price changes on Spanish and Euro area consumer price inflation. Economic Modelling, 28, 422-431.

Arshad, F., Awad, A., \& Hameed, A. (2009). The long run relationship between petroleum and cereals prices. Global Economy \& Finance Journal, 2(2), 91-100.

Avalos, F. (2014). Do oil prices drive food prices? The tale of a structural break. Journal of International Money and Finance, 42, 253-271.

Baek, J., \& Koo, W. W. (2010). Analyzing factors affecting U.S. food price inflation. Canadian Journal of Agricultural Economics, 58, 303-320.

Baffes, J. (2007). Oil spills on other commodities. Resources Policy, 32(30), 126-34.

Baumeister, C., \& Kilian, L. (2014). Do oil price increases cause higher food prices? Economic Policy, 29(80), 691-747.

Chang, T. H., \& Su, H. M. (2010). The substitutive effect of biofuels on fossil fuels in the lower and higher crude oil price periods. Energy, 35, 2807-2813.

Chen, S., Kuo, H., \& Chen, C. (2010). Modeling the relationship between the oil price and global food prices. Applied Energy, 87(8), 2517-2525.

Dickey, D. A., \& Fuller, W. A. (1981). Likelihood ratio statistics for autoregressive time series with a unit root. Econometrica, 49(4), 1057-1072.

Ibrahim, M. H. (2015). Oil and food prices in Malaysia: A nonlinear ARDL analysis. Agricultural and Food Economics, 3(2), 1-14.

Imai, K., Gaiha, R., \& Thapa, G. (2008). Food and oil prices. The School of Economics Discussion Paper Series, The University of Manchester.

Karakotsios, A., Katrakilidis, C., \& Kroupis, N. (2021). The dynamic linkages between food prices and oil prices. Does asymmetry matter? The Journal of Economic Asymmetries, 23(C).

Katusiime, L. (2018). Investigating spillover effects between foreign exchange rate volatility and commodity price volatility in Uganda. Economies, 7(1), 1-17.

Konandreas, P. (2012). Trade policy responses to food price volatility in poor net food-importing countries. ICTSD Programme on Agricultural Trade and Sustainable Development. Issue Paper No. 42. Geneva: International Centre for Trade and Sustainable Development.

Meyer, D. F., Sanusi, K. A., \& Hassan, A. (2018). Analysis of the asymmetric impacts of oil prices on food prices in oilexporting, developing countries. Journal of International Studies, 11(3), 82-94.

Moss, C. B., Livanis, G. T., \& Schmitz, A. (2010). The effect of increased energy prices on agriculture: A differential supply approach. Journal of Agricultural and Applied Economics, 42(4), 1-8.

Nazlioglu, S., \& Soytas, U. (2012). Oil price, agricultural commodity prices, and the dollar: A panel cointegration and causality analysis. Energy Economics, 34, 1098-1104.

Olasunkanmi, O. I., \& Oladele, K. S. (2018). Oil price shock and agricultural commodity prices in Nigeria: A non-linear autoregressive distributed lag (NARDL) approach. African Journal of Economic Review, 6(2), 74-91.

Pala, A. (2013). Structural breaks, cointegration, and causality by VECM analysis of crude oil and food price. International Journal of Energy Economics and Policy, Econjournals, 3(3), 238-246.

Pesaran, M. H., Shin, Y., \& Smith, R. J. (2001). Bounds testing approaches to the analysis of level relationships. Journal of Applied Econometrics, 16(3), 289-326.

Phillips, P. C. B., \& Perron, P. (1988). Testing for a unit root in time series regression. Biometrika,75(2), 335-346.

Reboredo, J. C., \& Ugando, M. (2014). US dollar exchange rate and food price dependence: Implications for portfolio risk management. North American Journal of Economics and Finance, 30, 72-89. 
Roache, S. K. (2010). What explains the rise in food price volatility? IMF Working Paper No. 10/129.

Roman, M., Górecka, A., \& Domagała, J. (2020). The linkages between crude oil and food prices. Energies, $13(24), 6545$.

Shin, Y., Yu, B., \& Greenwood-Nimmo, M. (2014). Modelling asymmetric cointegration and dynamic multipliers in a nonlinear ARDL framework. In: W. Horrace \& R. Sickles (ed.), Festschrift in Honor of Peter Schmidt (Vol. 44) (pp. 281-314). New York, NY: Springer.

TCMB, (2021). Enflasyon raporu (2021-I). https://www.tcmb.gov.tr/wps/wcm/connect/TR/TCMB+TR/ Main+Menu/Yayinlar/Raporlar/Enflasyon+Raporu/2021/Enflasyon+Raporu+2021+-+I (Erişim Tarihi: 12 Mart 2021).

Turan, T., \& Karakaş, M. (2018). Devlet harcamaları ve gelirleri arasındaki ilişki: Doğrusal olmayan sınır testi yaklaşımı (NARDL). Sosyoekonomi, 26(36), 33-48.

Türkiye İstatistik Kurumu (TUIK), (2021). $37379 \quad$ sayılı haber bülteni. https://data.tuik.gov.tr/Bulten/Index?p=T\%C3\%BCketici-Fiyat-Endeksi-Ocak-2021-37379\&dil=1 (Erişim Tarihi: 27 Şubat 2021).

Wang, Y., Wu, C., \& Yang, L. (2014). Oil price shocks and agricultural commodity prices. Energy Economics, 44, 22-35.

Wei Su, C., Wang, X., Tao, R., \& Oana-Ramona, L. (2019). Do oil prices drive agricultural commodity prices? Further evidence in a global bio-energy context. Energy, 172(C), 691-701.

Wong, K. K., \& Shamsudin, M. N. (2017). Impact of crude oil price, exchange rates and real GDP on Malaysia's food price fluctuations: Symmetric or asymmetric? International Journal of Economics and Management, 11(1), 259-275.

Zhang, C., \& Qu, X. (2015). The effect of global oil price shocks on China's agricultural commodities. Energy Economics, 51, 354-364. 


\section{Ekler}

Ek 1. Tanımlayıcı İstatistikler

\begin{tabular}{lccccc}
\hline & FP & OP & EP & EXR & IPI \\
\cline { 2 - 6 } Ortalama & 295,197 & 79,66667 & 284,3611 & 2,899613 & 96,1432 \\
Medyan & 277,435 & 75,225 & 273,3 & 2,31216 & 95,88425 \\
Maksimum & 507,12 & 126,59 & 443,55 & 6,37834 & 120,0263 \\
Minimum & 175,78 & 33,14 & 194,69 & 1,4253 & 63,58937 \\
Standart Sapma & 94,98733 & 26,11663 & 63,35625 & 1,387852 & 14,93113 \\
Çarpıklık & 0,794677 & 0,102298 & 0,770779 & 1,00995 & $-0,25055$ \\
Basıklık & 2,614575 & 1,611535 & 2,940651 & 2,84232 & 2,024561 \\
Gözlem & 120 & 120 & 120 & 120 & 120 \\
\hline
\end{tabular}


This Page Intentionally Left Blank 